\title{
Lack of association between catalase gene polymorphism (T/C exon 9) and susceptibility to vitiligo in a Turkish population
}

H. Bulut ${ }^{1}$, M. Pehlivan², S. Alper ${ }^{3}$, A.G. Tomatir ${ }^{4}$, H. Onay ${ }^{5}$, S.E. Yüksel ${ }^{3}$, F. Özkinay ${ }^{5}$ and S. Pehlivan ${ }^{5,6}$

${ }^{1}$ Department of Biology, Faculty of Science, Ege University, Izmir, Turkey

${ }^{2}$ Department of Hematology, Medical Faculty, Gaziantep University, Gaziantep, Turkey

${ }^{3}$ Department of Dermatology, Faculty of Medicine, Ege University, Izmir, Turkey

${ }^{4}$ Department of Medical Biology, Medical Faculty, Pamukkale University, Denizli, Turkey

${ }^{5}$ Genetic Diseases Research and Application Center, Ege University, Izmir, Turkey

${ }^{6}$ Department of Medical Biology, Medical Faculty, Gaziantep University,

Gaziantep, Turkey

Corresponding author: A.G. Tomatir

E-mail: tomatir@pau.edu.tr / aysegaye@hotmail.com

Genet. Mol. Res. 10 (4): 4126-4132 (2011)

Received April 29, 2011

Accepted September 23, 2011

Published October 31, 2011

DOI http://dx.doi.org/10.4238/2011.October.31.12

ABSTRACT. Accumulation of hydrogen peroxide $\left(\mathrm{H}_{2} \mathrm{O}_{2}\right)$ and low catalase (CAT) activity have been demonstrated in the epidermis of vitiligo patients. We investigated a possible association between the CAT exon 9 (Asp-389) gene and vitiligo susceptibility in the Turkish population. Thirty-four patients with vitiligo and 49 gender, age and ethnic matched controls were enrolled in the study. Genotyping was done by PCR-RFLP. The CAT exon 9 (Asp-389) genotype and allele frequencies of vitiligo patients did not differ significantly from those of 
healthy controls. We found no association between CAT(Asp-389) gene polymorphism and vitiligo susceptibility in Turkish vitiligo patients.

Key words: Melanocytes; Oxidative stress catalase gene (CAT); PCR-RFLP; Vitiligo

\section{INTRODUCTION}

Vitiligo (MIM193200) is the most common depigmentation disorder of the skin and hair that results from a selective destruction of melanocytes (Hann and Nordlund, 2000). It has been reported that vitiligo can affect all populations worldwide with diverse prevalence rates ranging from 0.1 to $2 \%$ in different geographical regions and ethnic groups (Hafez et al., 1983; Das et al., 1985a; Hann and Nordlund, 2000; Alkhateeb et al., 2003).

The etiology of vitiligo is still unknown, although the disease was first noted in approximately 1500 B.C. (Hann and Nordlund, 2000). Several theories have been proposed to explain the pathogenesis of vitiligo, including self-destructive, biochemical, neural, autoimmune and genetic hypotheses (Hann and Nordlund, 2000). Epidemiological studies have shown that vitiligo tends to aggregate in families (Das et al., 1985b; Majumder et al., 1993; Nath et al., 1994; Barona et al., 1995; Alkhateeb et al., 2003; Zhang et al., 2004a). About 20\% of vitiligo patients have at least one first-degree relative with vitiligo. The relative risk of developing vitiligo is increased 7 - to 10 -fold in first degree relatives of vitiligo patients (Nath et al., 1994).

The familial aggregation of vitiligo has been noted as early as 1933 (Hann and Nordlund, 2000). In order to clarify the genetic and environmental contributions to the familial character of the disease, epidemiological surveys have been conducted in many countries and various ethnic populations (Mehta et al., 1973; Howitz et al., 1977; Nordlund, 1997; Majumder et al., 1993; Nath et al., 1994; Alkhateeb et al., 2003; Zhang et al., 2004b). Although vitiligo clusters in families, it does not appear to segregate in a simple Mendelian pattern (Majumder et al., 1988, 1993; Nath et al., 1994; Alkhateeb et al., 2003). The aggregation of vitiligo in families observed in several studies suggests that vitiligo is a genetically or environmentally determined disease (Das et al., 1985b; Majumder et al., 1993; Nath et al., 1994). The complex genetics of vitiligo probably involves multiple susceptibility loci, genetic heterogeneity and incomplete penetrance with gene-gene and gene-environment interactions (Zhang et al., 2005). Increasing number of studies have demonstrated that certain genes are crucial for the development of vitiligo (Le Poole et al., 2001; Arcos-Burgos, 2002; Casp et al., 2002, 2003; Zhang et al., 2004a; Jin et al., 2004; Yang et al., 2005). Moreover, more than one genome-wide screen has localized vitiligo susceptibility loci on several chromosomes (Alkhateeb, 2002; Fain et al., 2003; Spritz et al., 2004; Chen et al., 2005).

Studies have demonstrated that the amount of hydrogen peroxide $\left(\mathrm{H}_{2} \mathrm{O}_{2}\right)$ in the skin of patients with vitiligo is significantly higher compared to the control group, while catalase enzyme activity is lower (Schallreuter et al., 1999). Other studies have also demonstrated the accumulation of $\mathrm{H}_{2} \mathrm{O}_{2}$ and low catalase activity in the epidermis of vitiligo patients (Schallreuter et al., 1991; Maresca et al., 1997). Catalase is the enzyme that catalyzes the conversion of hydrogen peroxide to water and oxygen, thereby preventing cellular damage due to highly reactive oxygen-derived free radicals. The CAT gene was selected as a candidate gene because of the 
reduction of catalase enzyme activity and concomitant accumulation of excess hydrogen peroxide observed in the entire epidermis of vitiligo patients (Schallreuter et al., 1999). The CAT gene consists of 13 exons spanning $34 \mathrm{~kb}$ of genomic DNA located at $11 \mathrm{p} 13$ with the complete cDNA sequence revealing a coding region of 1581 base pairs in length (Bell et al., 1986). An association has been established between vitiligo and a single nucleotide polymorphism (SNP) in exon 9 of the CAT gene (Casp et al., 2002). It has been documented that $\mathrm{T} / \mathrm{C}$ heterozygotes are more frequent among vitiligo patients than controls, and that the $\mathrm{C}$ allele is transmitted more frequently to patients with vitiligo compared to controls, suggesting that linked mutations in or near the CAT gene may contribute to a quantitative deficiency of catalase activity in the epidermis and accumulation of excess hydrogen peroxide (Casp et al., 2002).

Earlier, the T/C SNP in exon 9 of the CAT gene was found to be informative in terms of the DNA analysis of Caucasian vitiligo patients and control subjects. This region contains hidden changes which constitute informative gene markers for the catalase gene. Asp-389 is coded by both GAU and GUC, and thus the T/C difference in the gene sequence does not change the amino acid sequence. The objective of this study was to determine a possible association between the $C A T$ gene and vitiligo susceptibility in a Turkish population using this marker.

\section{MATERIAL AND METHODS}

\section{Study participants}

Thirty-four Turkish vitiligo patients (14 men and 20 women) were examined at the Department of Dermatology, Ege University Medical Faculty. Family history of vitiligo was present in $25 \%$ of the patients with vitiligo. Forty-nine sex-, age- and ethnicity-matched subjects without any clinical evidence of vitiligo were enrolled in the control group. The study was approved by the local institutional ethics committee and was conducted according to the Declaration of Helsinki of 1975. All participants were informed about the nature of the study, and written informed consent was obtained.

\section{Catalase gene polymorphisms}

SNP was identified in a T/C polymorphism in exon 9 (NCBI, dbSNP number rs769217) (Park et al., 2006). DNA samples were isolated from blood samples obtained from 34 vitiligo patients and 49 healthy controls using the King Fisher Genomic DNA Purification kit. Samples (100 ng) were submitted to 35 amplification cycles in a Perkin Elmer GeneAmp PCR system 9600 amplification machine, where each cycle consisted of denaturation at $94^{\circ} \mathrm{C}$ for $30 \mathrm{~s}$, annealing for $30 \mathrm{~s}$ and extension at $72^{\circ} \mathrm{C}$ for $30 \mathrm{~s}$, and a final extension step of incubation at $72^{\circ} \mathrm{C}$ for $5 \mathrm{~min}$. Following an overnight restriction digestion of the PCR products under the conditions specified by the enzyme supplier, DNA fragments were separated by $3 \%$ agarose gel electrophoresis and stained with ethidium bromide (Park et al., 2006).

The allele discrepancies in the series of PCR products were evaluated using the restriction enzyme (BstX1) (CCANNNNNNTGG). The prepared mixture (12 $\mu \mathrm{L}$ PCR product, 
$\mu \mathrm{L}$ buffer, $2.5 \mu \mathrm{L}$ BstX1) was put in a $0.5 \mathrm{~mL}$ Eppendorf tube and sealed with paraffin. After a short period of centrifugation, the mixture was incubated for $16 \mathrm{~h}$ at $55^{\circ} \mathrm{C}$. Cutting occurred if the CAT gene was a $\mathrm{T}$ allele; however, no cutting occurred in the case of a $\mathrm{C}$ allele. In the latter case (homozygous C), no change was observed in the size of this DNA piece. In the former case where enzyme cutting occurred, the 202-bp DNA fragment was cut into two parts of 98 and $104 \mathrm{bp}$. The homozygous $\mathrm{T}$ allele was differentiated by the strong appearance of these bands.

\section{Statistical analysis}

Distribution of the genotypes in patient and control groups was compared using the chi-square $\left(\chi^{2}\right)$ test. Hardy-Weinberg equilibrium (HWE) was determined using the test provided by the Institute of Human Genetics, Technical University Munich (http://ihg.gsf.de/cgi. bin/hw/hwa1.pl). P values $<0.05$ were considered statistically significant.

\section{RESULTS}

The allele and genotype frequencies of the single nucleotide polymorphism (T/C) in the 9th exon of the catalase gene of the control and patient groups are shown in Table 1. In the comparison of allele frequencies between the control and patient groups, no significant difference was found in the exon Bstx1 $(\mathrm{T} / \mathrm{C})$ polymorphism in the catalase gene $(\mathrm{P}=0.20)$. No significant difference was found between the genotypic frequencies of the control and patient groups determined by the expected value of the $\chi^{2}$-test as shown in Table 1. Similarly, there were no significant differences in the comparison of genotypic frequencies of the control and the patient groups $(\mathrm{P}=0.09)$. The ratio of heterozygote and homozygotes in the entire population was calculated theoretically using the Hardy-Weinberg equation. Values obtained from the Hardy-Weinberg equation were $64 \%$ for CC homozygotes $(0.8 \times 0.8=64), 32 \%$ for CT heterozygotes $(0.8 \times 0.2 \times 0.2=0.32)$, and $4 \%$ for TT homozygotes $(0.2 \times 0.2=0.04)$. The genetic allele frequencies of the patient populations showed a significant deviation from Hardy-Weinberg equilibrium.

\begin{tabular}{|c|c|c|c|}
\hline CAT gene (Asp-389) & Control $(\mathrm{N}=49)$ & Vitiligo $(\mathrm{N}=34)$ & $\mathrm{P}$ \\
\hline \multicolumn{4}{|l|}{ Genotypes } \\
\hline $\mathrm{CC}$ & $43(87.7)$ & $28(82.3)$ & 0.086 \\
\hline $\mathrm{CT}$ & $6(12.3)$ & $4(11.8)$ & 0.972 \\
\hline TT & $0(0)$ & $2(5.9)$ & 0.121 \\
\hline $\mathrm{CC}+\mathrm{CT}$ & $49(100)$ & $32(94.1)$ & 0.085 \\
\hline $\mathrm{CT}+\mathrm{TT}$ & $6(12.3)$ & $6(17.6)$ & 0.491 \\
\hline Total & $49(100)$ & $34(100)$ & \\
\hline \multicolumn{4}{|l|}{ Alleles } \\
\hline $\mathrm{C}$ & $92(93.9)$ & $60(88.2)$ & 0.198 \\
\hline $\mathrm{T}$ & $6(6.1)$ & $8(11.8)$ & \\
\hline Total & $98(100)$ & $68(100)$ & \\
\hline *HWE $\mathrm{p}$ & 0.648 & 0.011 & \\
\hline
\end{tabular}

Data are reported as number with percent in parentheses. $* \mathrm{HWE}=$ Hardy-Weinberg equilibrium, 


\section{DISCUSSION}

The relationship between the polymorphisms of the catalase enzyme and various diseases have been investigated (Góth et al., 2001). The C/T endemic polymorphism in the initial part of the catalase enzyme is effective in binding transcription factors. In a study performed in the Swedish population using a restriction enzyme, the $\mathrm{T}$ allele frequency was been found to be $28 \%$, and the catalase enzyme activity was found to be higher in the groups with the $\mathrm{T}$ allele compared to groups with the $\mathrm{C}$ allele $(\mathrm{P}<0.03)$ (Forsberg et al., 2001).

Although it has been observed that a single $(\mathrm{T} / \mathrm{C})$ nucleotide polymorphism in the 9th exon of the catalase enzyme may be considered to have a role in the disposition for vitiligo (Casp et al., 2002; Park et al., 2006; Gavalas et al., 2006; Em et al., 2007), there are no studies that have investigated the role of this polymorphism in the etiology of vitiligo in the Turkish population.

Casp et al. (2002) reported an association between susceptibility to vitiligo and a C/T SNP in codon 389 of the CAT gene in a North American population. Gavalas et al. (2006) suggested that the CAT gene C/T SNP is associated with susceptibility to vitiligo, with the $\mathrm{C} / \mathrm{T}$ genotype being significantly more frequent among vitiligo patients compared to healthy controls. However, it has not yet been established how the CAT gene C/T SNP could result in low catalase levels, and it is unlikely to affect the catalase activity directly since the variation results in a silent substitution of the aspartate residue at codon 389. Alternatively, this genetic marker could be linked to other CAT mutations that are deleterious in terms of the expression of CAT or the activity of catalase (Gavalas et al., 2006). The distribution of CAT gene genotype and allele frequencies have not been shown to differ significantly between vitiligo patients and normal controls, and the difference in haplotype distribution of catalase between vitiligo patients and normal controls has suggested a possible relationship between CAT gene and vitiligo susceptibility (Park et al., 2006). Em et al. (2007) showed that the well-documented CAT exon $9 \mathrm{~T} / \mathrm{C}$ may not be associated with Gujarat vitiligo patients.

Lv et al. (2011) found a significant correlation between the CAT T/C exon 9 polymorphism and the risk of vitiligo. Casp et al. (2002) and Gavalas et al. (2006) demonstrated an association between vitiligo susceptibility and CAT T/C SNP at codon 389 in Caucasian and English populations, respectively. However, in Korean (Park et al., 2006) and Gujarat (Em et al., 2007) populations, the distribution of T/C CAT exon 9 genotype and allele frequencies were not significantly associated with vitiligo which is in accordance with the results of our study.

In conclusion, we suggest that the enzyme catalase is involved in a genetic effect in vitiligo. Further studies should be performed with greater sample size to verify these results. Studies performed with catalase have shown that reformation of pigments is important in preventing vitiligo. Although the exact role of catalase in the development of vitiligo is not yet known, catalase is has been proven to have an effect in the treatment of this disease. Therefore, further studies should be performed with this enzyme to elucidate its role in the pathogenesis of vitiligo.

\section{ACKNOWLEDGMENTS}

Research supported by the Ege University (Grant \#2003/Fen/028). 


\section{REFERENCES}

Alkhateeb A, Stetler GL, Old W, Talbert J, et al. (2002). Mapping of an autoimmunity susceptibility locus (AIS1) to chromosome 1p31.3-p32.2. Hum. Mol. Genet. 11: 661-667.

Alkhateeb A, Fain PR, Thody A, Bennett DC, et al. (2003). Epidemiology of vitiligo and associated autoimmune diseases in Caucasian probands and their families. Pigment Cell Res. 16: 208-214.

Arcos-Burgos M, Parodi E, Salgar M, Bedoya E, et al. (2002). Vitiligo: complex segregation and linkage disequilibrium analyses with respect to microsatellite loci spanning the HLA. Hum. Genet. 110: 334-342.

Barona MI, Arrunategui A, Falabella R and Alzate A (1995). An epidemiologic case-control study in a population with vitiligo. J. Am. Acad. Dermatol. 33: 621-625.

Bell GI, Najarian RC, Mullenbach GT and Hallewell RA (1986). cDNA sequence coding for human kidney catalase. Nucleic Acids Res. 14: 5561-5562.

Casp CB, She JX and McCormack WT (2002). Genetic association of the catalase gene (CAT) with vitiligo susceptibility. Pigment Cell Res. 15: 62-66.

Casp CB, She JX and McCormack WT (2003). Genes of the LMP/TAP cluster are associated with the human autoimmune disease vitiligo. Genes Immun. 4: 492-499.

Chen JJ, Huang W, Gui JP, Yang S, et al. (2005). A novel linkage to generalized vitiligo on 4q13-q21 identified in a genomewide linkage analysis of Chinese families. Am. J. Hum. Genet. 76: 1057-1065.

Das SK, Majumder PP, Chakraborty R, Majumdar TK, et al. (1985a). Studies on vitiligo. I. Epidemiological profile in Calcutta, India. Genet. Epidemiol. 2: 71-78.

Das SK, Majumder PP, Majumdar TK and Haldar B (1985b). Studies on vitiligo. II. Familial aggregation and genetics. Genet. Epidemiol. 2: 255-262.

Em S, Laddha NC, Chatterjee S, Gani AR, et al. (2007). Association of catalase T/C exon 9 and glutathione peroxidase codon 200 polymorphisms in relation to their activities and oxidative stress with vitiligo susceptibility in Gujarat population. Pigment Cell Res. 20: 405-407.

Fain PR, Gowan K, LaBerge GS, Alkhateeb A, et al. (2003). A genomewide screen for generalized vitiligo: confirmation of AIS1 on chromosome 1p31 and evidence for additional susceptibility loci. Am. J. Hum. Genet. 72: 1560-1564.

Forsberg L, Lyrenas L, de FU and Morgenstern R (2001). A common functional C-T substitution polymorphism in the promoter region of the human catalase gene influences transcription factor binding, reporter gene transcription and is correlated to blood catalase levels. Free Radic. Biol. Med. 30: 500-505.

Gavalas NG, Akhtar S, Gawkrodger DJ, Watson PF, et al. (2006). Analysis of allelic variants in the catalase gene in patients with the skin depigmenting disorder vitiligo. Biochem. Biophys. Res. Commun. 345: 1586-1591.

Góth L, Rass P and Madarasi I (2001). A novel catalase mutation detected by polymerase chain reaction-single strand conformation polymorphism, nucleotide sequencing, and western blot analyses is responsible for the type $\mathrm{C}$ of Hungarian acatalasemia. Electrophoresis 22: 49-51.

Hafez M, Sharaf L and Abd el-Nabi SM (1983). The genetics of vitiligo. Acta Derm. Venereol. 63: 249-251.

Hann SK and Nordlund JJ (2000). Vitiligo. Blackwell Science, Oxford.

Howitz J, Brodthagen H, Schwartz M and Thomsen K (1977). Prevalence of vitiligo. Epidemiological survey on the Isle of Bornholm, Denmark. Arch. Dermatol. 113: 47-52.

Jin SY, Park HH, Li GZ, Lee HJ, et al. (2004). Association of angiotensin converting enzyme gene I/D polymorphism of vitiligo in Korean population. Pigment Cell Res. 17: 84-86.

Le Poole IC, Sarangarajan R, Zhao Y, Stennett LS, et al. (2001). 'VIT1', a novel gene associated with vitiligo. Pigment Cell Res. 14: 475-484.

Lv YJ, Liao WJ, Luan Q, Wang H, et al. (2011). The polymorphism of catalase T/C codon 389 in exon 9 and vitiligo susceptibility: a meta-analysis. J. Eur. Acad. Dermatol. Venereol. 25: 955-958.

Majumder PP, Das SK and Li CC (1988). A genetical model for vitiligo. Am. J. Hum. Genet. 43: 119-125.

Majumder PP, Nordlund JJ and Nath SK (1993). Pattern of familial aggregation of vitiligo. Arch. Dermatol. 129: 994-998.

Maresca V, Roccella M, Roccella F, Camera E, et al. (1997). Increased sensitivity to peroxidative agents as a possible pathogenic factor of melanocyte damage in vitiligo. J. Invest. Dermatol. 109: 310-313.

Mehta NR, Shah KC, Theodore C, Vyas VP, et al. (1973). Epidemiological study of vitiligo in Surat area, South Gujarat. Indian J. Med. Res. 61: 145-154.

Nath SK, Majumder PP and Nordlund JJ (1994). Genetic epidemiology of vitiligo: multilocus recessivity cross-validated. Am. J. Hum. Genet. 55: 981-990.

Nordlund JJ (1997). The epidemiology and genetics of vitiligo. Clin. Dermatol. 15: 875-878.

Park HH, Ha E, Uhm YK, Jin SY, et al. (2006). Association study between catalase gene polymorphisms and the 
susceptibility to vitiligo in Korean population. Exp. Dermatol. 15: 377-380.

Schallreuter KU, Wood JM and Berger J (1991). Low catalase levels in the epidermis of patients with vitiligo. J. Invest. Dermatol. 97: 1081-1085.

Schallreuter KU, Moore J, Wood JM, Beazley WD, et al. (1999). In vivo and in vitro evidence for hydrogen peroxide $\left(\mathrm{H}_{2} \mathrm{O}_{2}\right)$ accumulation in the epidermis of patients with vitiligo and its successful removal by a UVB-activated pseudocatalase. J. Investig. Dermatol. Symp. Proc. 4: 91-96.

Spritz RA, Gowan K, Bennett DC and Fain PR (2004). Novel vitiligo susceptibility loci on chromosomes 7 (AIS2) and 8 (AIS3), confirmation of SLEV1 on chromosome 17, and their roles in an autoimmune diathesis. Am. J. Hum. Genet. 74: $188-191$.

Yang S, Wang JY, Gao M, Liu HS, et al. (2005). Association of HLA-DQA1 and DQB1 genes with vitiligo in Chinese Hans. Int. J. Dermatol. 44: 1022-1027.

Zhang XJ, Liu JB, Gui JP, Li M, et al. (2004a). Characteristics of genetic epidemiology and genetic models for vitiligo. $J$. Am. Acad. Dermatol. 51: 383-390.

Zhang XJ, Liu HS, Liang YH, Sun LD, et al. (2004b). Association of HLA class I alleles with vitiligo in Chinese Hans. $J$. Dermatol. Sci. 35: 165-168.

Zhang XJ, Chen JJ and Liu JB (2005). The genetic concept of vitiligo. J. Dermatol. Sci. 39: 137-146. 